\title{
Integrative Taxonomy of Meloidogyne oryzae (Nematoda: Meloidogyninae) parasitizing rice crops in Southern Brazil
}

\author{
Vanessa Silva da Mattos • Juvenil Enrique Cares - Cesar Bauer Gomes • \\ Ana Cristina Meneses Mendes Gomes • Jessica da Mata dos Santos Monteiro • \\ Guillermo Marcello Gomez • Philippe Castagnone-Sereno • \\ Regina Maria Dechechi Gomes Carneiro
}

Accepted: 7 December 2017 / Published online: 18 December 2017

(C) Koninklijke Nederlandse Planteziektenkundige Vereniging 2017

\begin{abstract}
A root-knot nematode parasitizing rice (Oryza sativa L.) in Santa Catarina state (Brazil) was identified as Meloidogyne oryzae Maas, Sanders and Dede, 1978 using different approaches. The specimens studied from this Brazilian population were compared with the type description of M. oryzae from Suriname, with additional morphological, biochemical and molecular characterization. The female has a longer stylet $(15.0 \mu \mathrm{m})$ when compared with $M$. graminicola $(11.2 \mu \mathrm{m})$ with irregularly shaped knobs, vulva offset and slightly protruding in posterior region. The lip region was distinct from first body annuli, and labial disc and the medial lips form an anchor-shaped structure. Perineal patterns were similar to M. graminicola. The male has a lip region offset and the presence of few short and irregular lines; medial lips divided, not fused with labial disc and stylet $(18.2 \mu \mathrm{m})$
\end{abstract}

V. S. da Mattos · J. E. Cares

Departamento de Fitopatologia, Universidade de Brasília, Brasília, DF 70910-900, Brazil

V. S. da Mattos - A. C. M. M. Gomes - J. d. d. Monteiro •

G. M. Gomez • R. M. D. G. Carneiro $(\bowtie)$

Embrapa Recursos Genéticos e Biotecnologia, C.P. 02372 ,

Brasília, DF 70849-979, Brazil

e-mail: regina.carneiro@embrapa.br

C. B. Gomes

Embrapa Clima Temperado, C.P. 403, Pelotas, RS 96001-970, Brazil

P. Castagnone-Sereno

INRA, CNRS, UMR 1355-7254, Institut Sophia Agrobiotech, University Nice Sophia Antipolis, 06900 Sophia Antipolis, France longer than in M. graminicola $(16.8 \mu \mathrm{m})$. Second-stage juvenile $(\mathrm{J} 2)$ tail $(75.8 \mu \mathrm{m})$ was longer than in M. graminicola $(70.9 \mu \mathrm{m})$ with a very long narrow hyaline portion $(22 \mu \mathrm{m}$ in $M$. oryzae and $17.9 \mu \mathrm{m}$ in M. graminicola). Biochemically, it presented a distinct esterase profile (Est $\mathrm{O} 1=\mathrm{R} 1$ ), differentiating it from M. graminicola (Est VS1). The number of chromosomes was $3 n=50-56$, and in DNA sequences of ITS1-5.8SITS2 rRNA the two populations of $M$. oryzae clustered together with other mitotic parthenogenetic species, differentiating them from M. graminicola with $n=18$ chromosomes and clustered with meiotic species. Phylogenetic analysis using neutral markers (AFLP and RAPD) showed that both $M$. oryzae populations form a coherent, closely related cluster separately from $M$. graminicola isolates. This study represented the first detection of M. oryzae in Brazil and the second in the world after the species description in 1971.

Keywords AFLP- esterase phenotype - ITS · morphology Oryza sativa $\cdot$ RAPD $\cdot$ root-knot nematode $\cdot$ taxonomy $\cdot$ tomato

\section{Introduction}

Many genera of parasitic nematodes are associated with rice, among which are several root-knot nematode (RKN) species, Meloidogyne spp. Almost all the RKN species described in rice belong to the so-called 'graminis-group'. They are morphologically similar (Jepson 1987) and their enzymatic characterization is 
difficult due to the large drawn-out bands and high enzymatic activity revealed on gels. Due to these similarities, some species may have been misidentified with other Meloidogyne spp. parasites of rice, especially with M. graminicola Golden and Birchfield 1965 (Negretti et al. 2017).

The rice RKN, $M$. graminicola, has emerged as the most widespread root-knot nematode in Brazil (Negretti et al. 2017), and worldwide in both subtropical and tropical regions. It is considered to be a major threat to the rice crop, particularly in Asia where changes in agricultural practices in response to climate change and socioeconomic conditions have led to a dramatic increase in M. graminicola and probably other species (Negretti et al. 2017; De Waele and Elsen 2007).

Meloidogyne oryzae Maas, Sanders and Dede, 1978 was first detected in 1971 in Suriname, causing damage to rice plants (Maas et al. 1978). Although valuable information using Light Microscopy (LM) was included in the original description (Maas et al. 1978), lack of Scanning Electron Microscopy (SEM) and biochemical/molecular data led to a limited characterization of the species. Although Jepson (1987) used SEM to provide additional information for the characterization of $M$. oryzae, little attention was given to this species for several years. More recently, M. oryzae was detected again in Suriname and French Guiana using only the esterase phenotype as a diagnostic character (Carneiro et al. 2000). Two similar non-specific esterase profiles have been already attributed to M. oryzae: VS1 (Esbenshade and Triantaphyllou 1985) and O1 (Carneiro et al. 2000). A new malate dehydrogenase profile MDH O3 (Rm 1.4, 1.6, 1.8) was also reported by the last authors. Although this second detection was performed using a topotype population from Suriname collected 20 years after the original description, the species-specific identity of this population was not confirmed by morphological approaches (Regina M.D.G. Carneiro unpublished). The same population was studied by Tigano et al. (2005) using $18 \mathrm{~s}$ rDNA sequences, and it clustered with meiotic parthenogenetic species in phylogenetic reconstruction, contradicting the fact that M. oryzae has 51-55 chromosomes and a mitotic parthenogenesis mode of reproduction (Esbenshade and Triantaphyllou 1985). This population from Suriname was studied later and presented $(n=18)$ chromosomes and an esterase phenotype similar to M. graminicola (Carneiro et al. 2000), confirming the suspicion of an erroneous identification (Negretti et al. 2017). Considering this additional information, $M$. oryzae had been detected only once in the world, in Suriname (1971), described by Maas et al. (1978) and later studied by Esbenshade and Triantaphyllou (1985) and Jepson (1987).

Meloidogyne species with an elevated perineum like M. oryzae were previously assigned to the genus Hypsoperine. This genus was proposed by Sledge and Golden in 1964 (Coetzee 1956) for Hypsoperine graminis as the type species and for $H$. acronea Coetzee 1956 (Araki 1992). These authors and Page (1985) believed that the new genus Hypsoperine occupied a position between Heterodera and Meloidogyne and presented females with eggs containing $\mathrm{J} 1$ and $\mathrm{J} 2$ and hatched $\mathrm{J} 2$ inside the bodies. However, the taxonomic status was in dispute for many years. Siddiqi synonymized Hypsoperine with Meloidogyne in 2000 (Siddiqi 2000). Recently, a phylogenetic tree inferred from $18 \mathrm{~S}$ sequences placed $M$. spartinae $(=H$. spartinae) within the genus Meloidogyne, which showed that Hypsoperine was a junior synonym of Meloidogyne (Plantard et al. 2007).

A recent survey in the south of Brazil detected Meloidogyne graminicola, M. javanica (Treub, 1885) Chitwood, 1949 and three other Meloidogyne spp. populations with atypical esterase phenotypes causing damage in rice-fields of Rio Grande do Sul (RS) and Santa Catarina (SC) states (Negretti et al. 2017). Considering the morphological, morphometrical, enzymatic and molecular differences in $M$. graminicola and other Meloidogyne species from rice, the aim of this study was to perform an integrative taxonomic description based on LM, SEM, ITS, AFLP, RAPD and isozyme phenotyping, which remains essential for accurate diagnosis (Hunt and Handoo 2009) of the unknown Meloidogyne sp.1 root-knot nematode populations found in SC state. The second objective was to clarify the mode of reproduction of these populations, by studying the cytology of the parasite and giving an evolutionary perspective using phylogeny. We also reported here the first occurrence of $M$. oryzae in the southern region of Brazil, and its second detection in the world after the species description.

\section{Materials and methods}

Nematode populations

Stock pure cultures of Meloidogyne spp., including two populations of Meloidogyne sp.1 populations from SC rice-fields (Negretti et al. 2017) (Table 1) were 
maintained on rice plants (Oryza sativa L.- 'BR-IRGA $\left.410^{\prime}\right)$ in greenhouse conditions $\left(25-28^{\circ} \mathrm{C}\right)$. All morphological and biochemical studies were done with these cultures. Egg masses and females were handpicked from infected rice roots, and second-stage juveniles (J2) were hatched in moist chambers. Males were obtained by placing roots with egg masses in water, aerating them with an aquarium pump and periodically collecting the specimens from the water (Carneiro et al. 1998).

Morphological studies

Male and second-stage juvenile (J2) nematodes were killed in cold $\left(5{ }^{\circ} \mathrm{C}\right) 2 \%$ formaldehyde and measured immediately under light microscope (LM). Perineal patterns were cut from live young females in $45 \%$ lactic acid and mounted in glycerin (Taylor and Netscher 1974). Male, J2, and female specimens were prepared for scanning electron microscopy (SEM) according to previously described methods (Eisenback and Hirschmann 1979, 1980; Eisenback et al. 1980). Specimens were viewed and photographed with a Zeiss DSM-962 scanning electron microscope. Both populations of Meloidogyne sp. 1 were investigated.

Biochemical and cytogenetic studies

Electrophoresis of the two Meloidogyne sp.1 populations from rice was performed on $7 \%$ polyacrylamide gel slabs isozymes in a horizontal electrophoresis system, according to Carneiro and Almeida (2001). Both esterase (EST) and malate dehydrogenase (MDH) enzymes were investigated. Meloidogyne javanica (EST J3, MDH N1) was used as reference. Cytogenetic studies were carried out with a propionic orcein staining method (Triantaphyllou 1985b).

\section{Molecular studies}

For the phylogenetic analyses, the ITS1-5.8S-ITS2 region of rRNA (primer set: 5367-5 -TTGATTAC GTCCCTGCCCTTT-3 _ and F195 -5_-TCCTCCGC TAAATGATATG-3_Schmitz et al. 1998) and the D2D3fragment of the 28S rRNA gene (primer set: D2A 5_-ACAAGTACCGTGAGGGAAAGTTG-3 _ and D3B- 5_-TCGGAAGGAACCAGCTACTA-3_; De Ley et al. 1999) were amplified according to Subbotin et al. (2000) conditions. PCR products were cleaned using the Wizard® SV Gel/PCR Clean-Up System (Promega) and cloned into the pGem-T® Easy Vector (Promega), following the manufacturer's instructions. Sequence alignments were performed using MEGA version 5.03 with default parameters (Tamura et al. 2011), with sequences obtained from the Meloidogyne spp. from rice (Table 1), and also with sequences of other Meloidogyne spp. retrieved from the NCBI database. A tree was generated using the Neighbour-Joining (NJ) algorithm (Saitou and Nei 1987) in PAUP* software version 4b10 (Swofford 2002). Sequences from Pratylenchus pinguicaudatus Rensch, 1924 Filipjev and Schuurmans Stekhoven, 1941 (KP995311.1) was used as outgroup. To test the node support of the generated trees, 1000 bootstrap replicates were performed and only values above $50 \%$ were considered.

As a different and complementary strategy to study the relationships between Meloidogyne species from rice, we further tested neutral AFLP and RAPD markers. For the analysis with RAPD markers, PCR reactions were performed according to Randig et al. (2002). Twenty-five 10-mer oligonucleotide primers (Operon Technologies) were used: OPA-12, OPAB-02, OPAS-08, OPAU-13, OPB-05, OPC-07, OPC-09, OPD-13, OPG-06, OPG-13, OPH-01, OPJ-17, OPK20, OPL-20, OPM-20, OPN-10, OPP-05, OPR-03, OPR-07, OPR-12, OPW-05, OPW-06, OPX-16, OPY06, OPZ-07. The amplification was performed on a PTC-100 thermocycler using the following settings: $5 \mathrm{~min}$ at $94{ }^{\circ} \mathrm{C}$ : 40 cycles of $30 \mathrm{~s}$ at $94{ }^{\circ} \mathrm{C}, 45 \mathrm{~s}$ at $36^{\circ} \mathrm{C}, 2 \mathrm{~min}$ at $70{ }^{\circ} \mathrm{C}$; and a final extension of $10 \mathrm{~min}$ at $70{ }^{\circ} \mathrm{C}$ (Randig et al. 2002). PCR products were separated by electrophoresis in a $1.5 \%(w / v)$ agarose gel, stained with ethidium bromide $\left(0.3 \mu \mathrm{g} \mathrm{ml}^{-1}\right)$ and visualised under UV light. In the AFLP analysis, DNA digestion were executed following the method of Suazo and Hall (1999). A total of six random 22-mer primers (Integrated DNA Technologies) were used, consisting of the EcoRI adapter core sequence 5_- GACTGCGT ACCAATTCAGT-3_plus the three_selective nucleotides (ACT, ATT, GGC, CAG, CCT and TCG) PCR reactions were performed in a $25 \mu \mathrm{l}$ final volume containing $1 \mu \mathrm{l}\left(50 \mathrm{ng} \mu \mathrm{l}^{-1}\right)$ digested DNA, $2.5 \mu \mathrm{l} 10 \times \mathrm{PCR}$ buffer without magnesium chloride (Invitrogen), $1 \mu \mathrm{l}$ $50 \mathrm{mM} \mathrm{MgCl2,0.5 \mu l} 10 \mathrm{mM}$ dNTPs, $1 \mu \mathrm{l} 10 \mu \mathrm{M}$ primer and $0.3 \mu \mathrm{l}$ TaqDNA polymerase $\left(5 \mathrm{U}^{-1} \mathrm{l}^{-1}\right.$; Invitrogen). DNA was amplified using a PTC-100 thermocycler (MJ Research) under the following cycling parameters: $1 \mathrm{~min}$ at $95^{\circ} \mathrm{C}: 37$ cycles of $1 \mathrm{~min}$ at 
Table 1 List of Meloidogyne spp. isolates used in this study: population code and origin

\begin{tabular}{lll}
\hline Population Code & Species & Origin $^{(\text {Municipality/State/Country) }}{ }^{\text {a }}$ \\
\hline Mg G2 & Meloidogyne graminicola & Guaramirim/SC/Brazil \\
Mg G4 & M. graminicola & Camburiú/SC/Brazil \\
Mg G6 & M. graminicola & Camburiú/SC/Brazil \\
Mg G8 & M. graminicola & Capão do Leão/RS/Brazil \\
Mg G12 & M. graminicola & Capão do Leão/RS/Brazil \\
Mg G13 & M. graminicola & Rio do Sul/SC/Brazil \\
Mg P & M. gramnicola & The Philippines \\
Msp 1-1 & Meloidogye sp.1 (=M. oryzae) & Ilhota/SC/Brazil \\
Msp 1-2 & Meloidogye sp.1 (=M. oryzae) & Camboriú/SC/Brazil \\
Msp 2 & Meloidogyne sp. 2 & Uruguaiana/RS/Brazil \\
Msp 3 & Meloidogyne sp. 3 & Uruguaiana/RS/Brazil \\
Ms & M. salasi & Costa Rica \\
\hline
\end{tabular}

${ }^{\mathrm{a}}$ Brazilian states: $\mathrm{RS}=$ Rio Grande do Sul and $\mathrm{SC}=$ Santa Catarina

${ }^{\mathrm{b}}$ M. graminicola from The Philippines population was donated by Dr. Gerrit Karssen (University of Wageningen, The Netherlands)/ Dutch NPPO (code: E8256)

${ }^{\mathrm{c}}$ M. salasi population was donated by Lorena Flores M.Sc (Universid de San José, Costa Rica)

$94{ }^{\circ} \mathrm{C}, 1 \mathrm{~min}$ at $56{ }^{\circ} \mathrm{C}, 2.5 \mathrm{~min}$ at $72{ }^{\circ} \mathrm{C}$; and a final extension of $10 \mathrm{~min}$ at $72{ }^{\circ} \mathrm{C}$ (Suazo and Hall 1999). PCR products were separated by electrophoresis in a $1.5 \%(\mathrm{w} / \mathrm{v})$ agarose-synergel $(0.7 \%$ agarose, $0.4 \%$ synergel; Diversified Biotech), stained with ethidium bromide $\left(0.3 \mu \mathrm{g} \mathrm{ml}^{-1}\right)$ and photographed under UV light. The analysis was repeated twice. DNA fingerprints were converted into a $0-1$ binary matrix and phylogenetic reconstruction was performed using the NJ algorithm (Saitou and Nei 1987) in PAUP v. $4 b 10$ (Swofford 2002), considering the data as unordered with no weighting. To test the node support of the generated trees, the analysis was performed on 1000 bootstrap replicates and only values above $50 \%$ were considered. As the AFLP and RAPD markers could be considered to be independent characters, the two data sets were combined into a global NJ analysis, using the total evidence approach proposed by Huelsenbeck et al. (1996). For both analysis, one population of each $M$. incognita and $M$. javanica were included.

\section{Results}

Morphological studies

Meloidogyne sp.1 incites large, elongated galls on rice plants, often at the root tip, which may become hooked, similar to M. graminicola (Fig. 1a). Females are completely embedded in the root tissue, where eggs are laid. All egg masses are internal. Males are not very frequent, but when present, they are often found inside the root together with the female and second-stage juveniles. In tomato, small galls are observed, usually located just behind the root tip and internal egg masses.

Females The body shape is elongated and globular pear-shaped with an off-set neck; coarse annuli in neck. The anterior end of the body is usually in line with the posterior end. The vulva is located on a slight posterior protuberance formed especially by the vulva lips (Fig. 1b), and it is observed in most of the specimens. The perineal patterns are round to oval-shaped; the dorsal arch smoothly rounded; no lateral incisures or gap observed. Phasmids are small (not always visible). The ridges on the cuticle in the dorsal region form wavy broken or unbroken irregular lines around and between the phasmids. Striae rather coarse and no vulva lip striae. The perivulval area usually free of striae. A prominent fold covers the anus dorsally, while in most specimens the ventral side is marked by a distinct rather thick fold or at least an obvious regular line (Fig. 2). The lip region is low and lips slightly off-set (Fig. 3a). Under Scanning electron microscope (SEM), lip region is distinct from first body annuli, labial disc and the medial lips form an anchor-shaped structure, and lateral lips are 

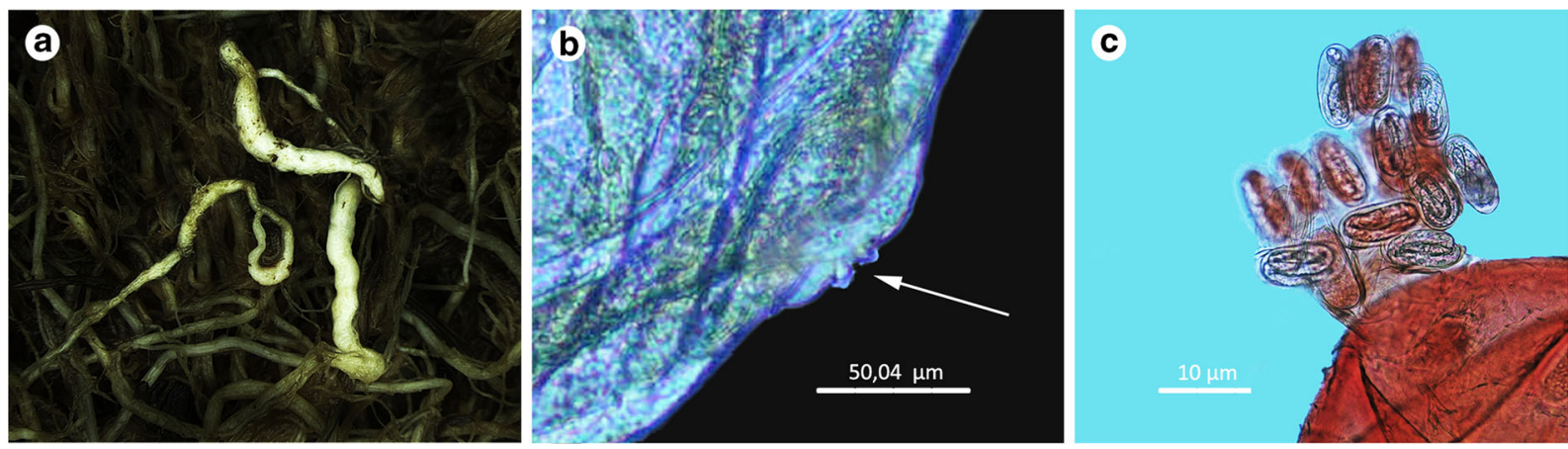

Fig. 1 Photomicrographs of M. oryzae: a- Galls formed by M. oryzae in rice roots; b-Protuberant vulva of M. oryzae female; c- Eggs containing $\mathrm{J} 1$ and $\mathrm{J} 2$ inside $M$. oryzae female body

not protuberant (Fig. 3b, c). First body annulus postlabial, apparently thicker than the subsequent ones. Excretory pore is located 2-3 stylet lengths behind the anterior region apex and anterior to the median bulb (Fig. 3a). The stylet conus sometimes curved dorsally (Fig. 3d, f). Stylet length 14-18 $\mu \mathrm{m}$; knobs generally set off from the shaft and sometimes presenting an irregular shape. The distance of the DEGO to the base of the stylet is $4-6 \mu \mathrm{m}$ (Fig. 3a, d-f, Table 2). Often, females containing eggs at different embryonic stages (including $\mathrm{J} 1$ and J2) and hatched J2 were observed within the female bodies (Fig. 1c).

Males Body vermiform, lip region is offset (Fig. 4a). Presence of few short, irregular lines in lip region
(Fig. 4b). Under SEM the labial disk and medial lips are fused, medial lips appear anchor-shaped and separated from labial disk by shallow depression in most of the specimens. Lateral lips are completely absent. The stylet is well-developed with knobs small and rounded, backwardly sloping onto shaft, the anterior part (conus) slightly shorter than the posterior part (shaft) (Fig. 4c, d). The stylet length is $18-20 \mu \mathrm{m}$ and DEGO is $4-6 \mu \mathrm{m}$. The lateral field occupies about $1 / 3$ of the body width and consists of 4-8 incisures, aerolated at mid-body (Fig. 4f), narrowing anteriorly, and posteriorly until the end of the tail. Under SEM, it is possible to observe noncontinuous lines or broken incisures on the lateral field. The tail is bluntly rounded with an unstriated
Fig. 2 Perineal patterns of Meloidogyne oryzae from Brazil. a-d: Light microscopy micrographs showing typical variation for this species
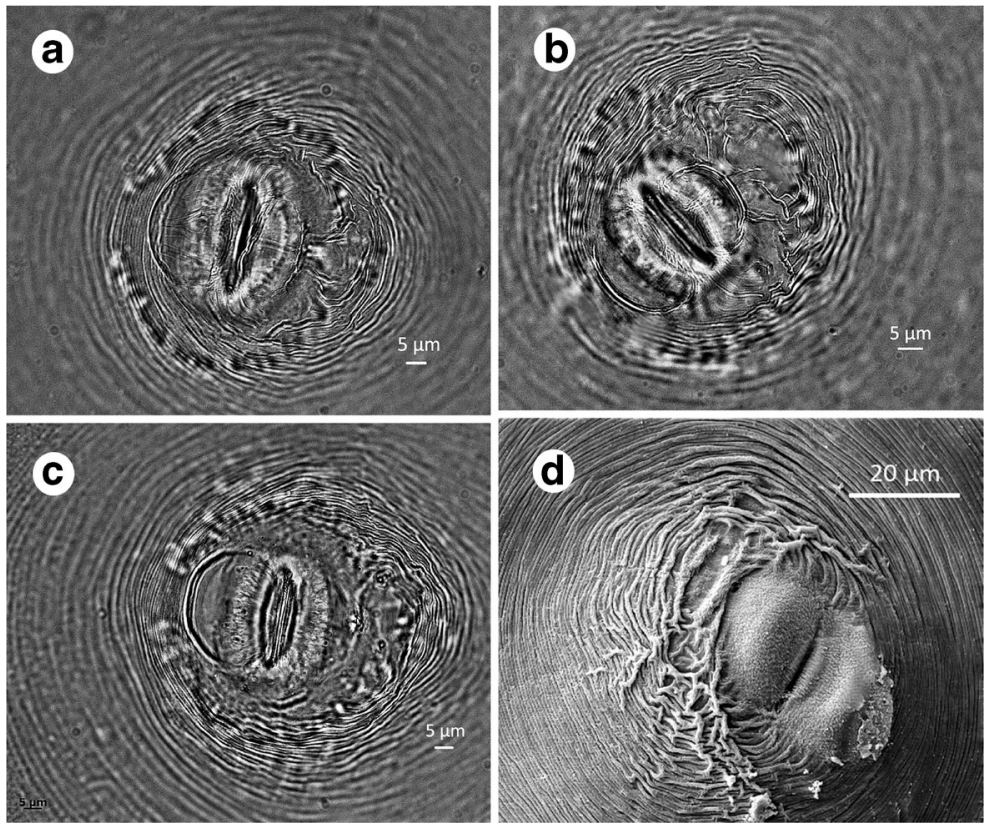
Fig. 3 F'emale of Meloidogyne oryzae from Brazil. a: Light microscopy micrographs of anterior region; $\mathbf{b}$ and $\mathbf{c}$ : Scanning electron microscopy (SEM) micrographs of anterior region; $\mathbf{d}, \mathbf{e}$, f: SEM micrographs of excised stylets
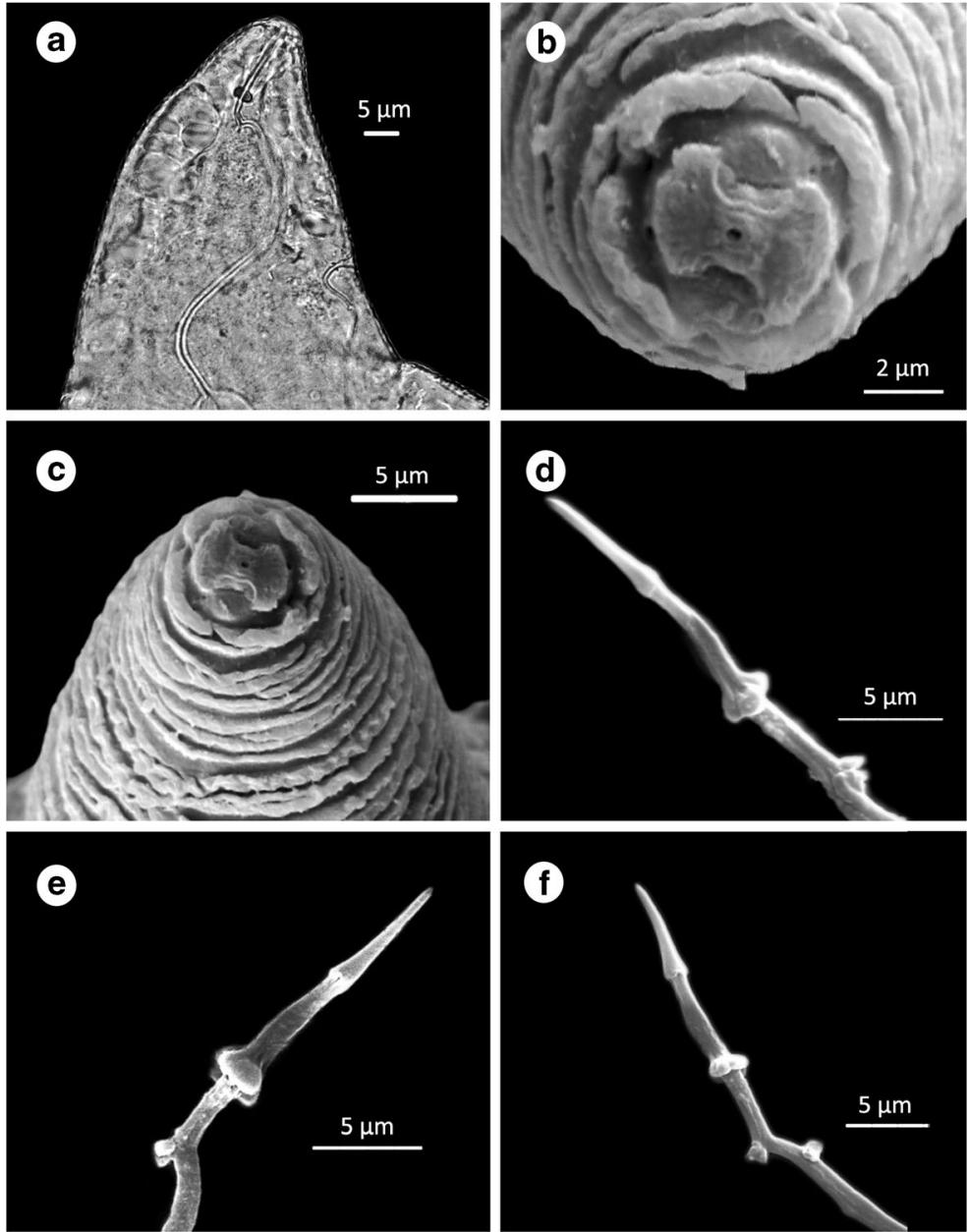

terminus (Fig. 4e). Gubernaculum 6-9 $\mu \mathrm{m}$ in length. Phasmids not observed.

Second stage juvenile The body is slender, vermiform, tapering gradually towards ends and clearly annulated. The lip is truncate and not offset (Fig. 5a), without annulations. Labial disc and medial lips are fused, dumbbell shaped (Fig. 5e). The stylet is very slender with small backward-sloping basal knobs (Fig. 5a). The stylet $(11-14 \mu \mathrm{m})$ and the DEGO (3-5 $\mu \mathrm{m})$ are longer when compared with M. graminicola: $11-12 \mu \mathrm{m}$ and 2.8-3.4 $\mu \mathrm{m}$. The lateral field consists of four areolated incisures (Fig. 5f). The tail is very long, conoid and thin, tapering to a long narrow hyaline portion, often appearing slightly clavate, with a clear unstriated terminal region and two or three cuticular constrictions (Fig. 5b-d). Phasmids posterior to anus very small, located in central incisures of lateral fields. The tail length is $66-85 \mu \mathrm{m}$ and the hyaline terminus is $19-24 \mu \mathrm{m}$. The rectum is inflated in most of the specimens.

Biochemical studies

Meloidogyne graminicola and Meloidogyne oryzae (=Meloidogyne sp.1) presented species-specific esterase phenotypes (Fig. 6) forming large drawn-out bands with high enzymatic activity. Meloidogyne graminicola presented esterase phenotype VS1, $\mathrm{Rm}=0.70$ with a large band, extending from 0.65 to 0.75 and $M$. oryzae Est $\mathrm{O} 1(\mathrm{Rm}=1.02)$, another large band extending from 1.0 to 1.4 . The same malate dehydrogenase phenotype (MDH N1a, RM: 1.4) was detected in both M. graminicola and M. oryzae. 
Eur J Plant Pathol (2018) 151:649-662

655

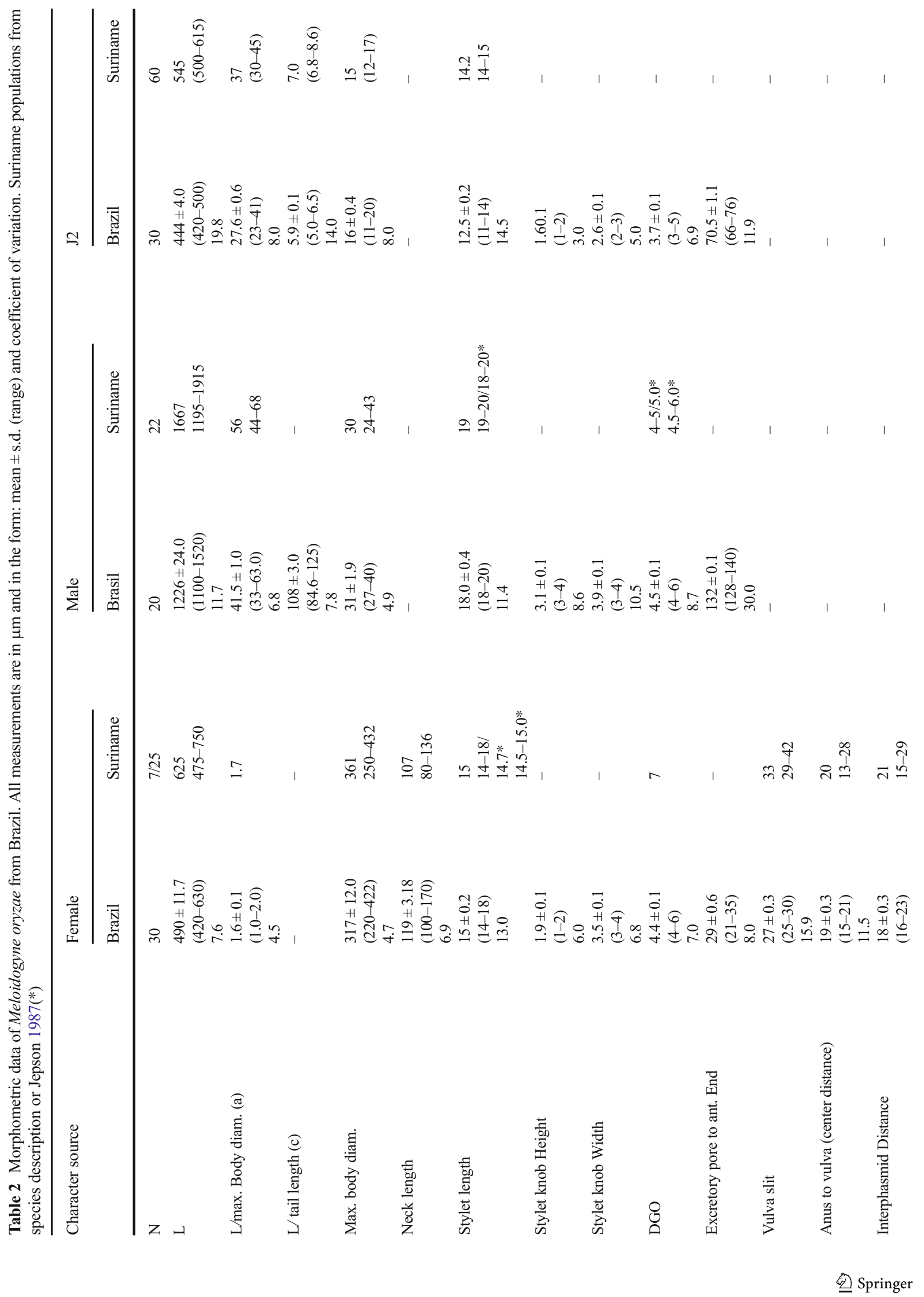




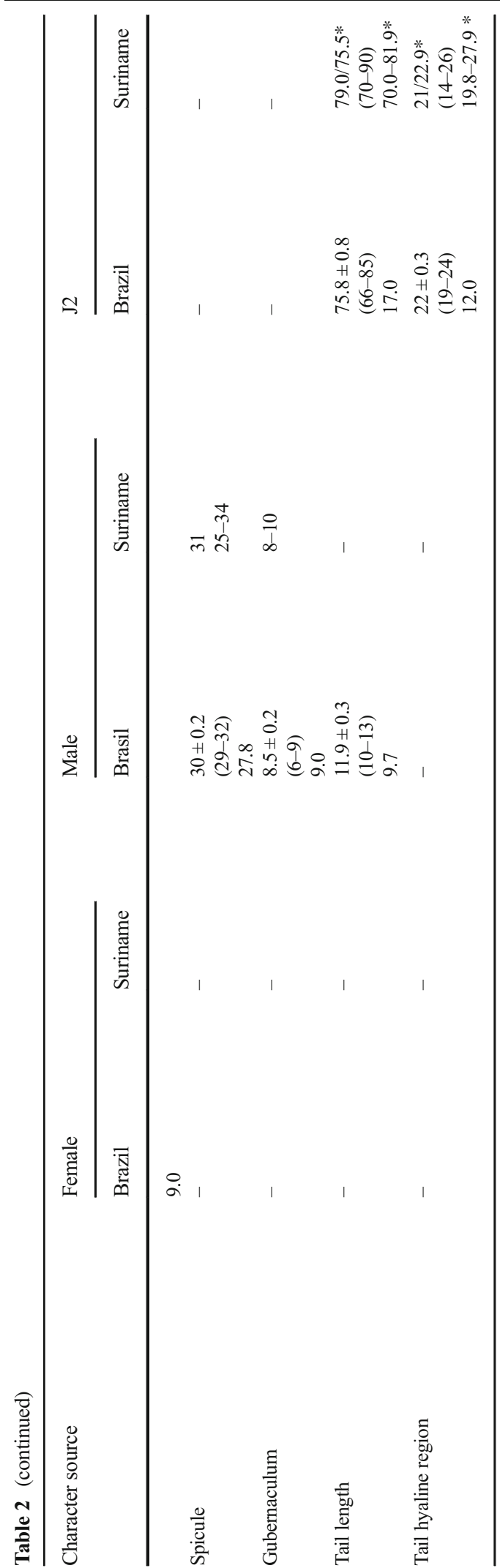

Cytogenetic studies

Meloidogyne oryzae from Brazil reproduces by mitotic parthenogenesis and presented the triploid form $(3 n=$ 50-56 chromosomes).

Molecular studies

Phylogenetic analyses were used to complement the results obtained by morphological and isozyme approaches, by comparing sequences of the ITS1-5.8SITS2 rRNA segment from closely related species and other Meloidogyne spp. sequences obtained from the GenBank. All new sequences were deposited in GenBank and the accession numbers are presented in Fig. 7. Phylogenetic analysis obtained for the ITS15.8S-ITS2 rRNA segment showed that the two M. oryzae populations clustered together with other obligatory mitotic parthenogenetic species (Fig. 7). Meloidogyne salasi Lopez, 1984 clustered wih M. graminicola populations and the unknown species Meloidogyne sp.2 and Meloidogyne sp.3 originating from rice in southern Brazil. The species belonging to the 'graminis-group' (M. graminicola, Meloidogyne sp.2, Meloidogyne sp.3, M. salasi and M. naasi Franklin, 1965) clustered together and separated from M. incognita, M. javanica and M. arenaria. Analysis for D2-D3 fragment of 28S rRNA presents a phylogenetic tree with less variability; this result was not included because it was not informative.

A total of 6 AFLP and 26 RAPD primers were used to infer the genetic diversity within Meloidogyne spp. Both markers reproduced together 664 polymorphic fragments for all 12 Meloidogyne spp. populations studied (584 of RAPD and 80 of AFLP). Overall, there was a high level of polymorphism observed within the M. graminicola isolates (72.5\%). For both Brazilian isolates of $M$. oryzae, $12.9 \%$ of polymorphism was recorded. The NJ trees (Fig. 8) were obtained after combining data from both markers together into one single analysis, and all species grouped together with high bootstrap and separately from each other. Meloidogyne oryzae populations clustered together in a single clade with $100 \%$ bootstrap support.

Diagnosis and relationships

In general, the morphology and morphometric data of the Meloidogyne sp.1 populations from Brazil 
Fig. 4 Male of Meloidogyne oryzae from Brazil. a: Light microscopy (LM) micrograph of anterior region in lateral view; $\mathbf{b}$ : Scanning electron microscopy (SEM) micrographs of anterior region; c: SEM micrograph of posterior region showing spicules, d: SEM micrograph of excised stylet; e: SEM micrograph of tail, f: SEM micrographs of lateral field
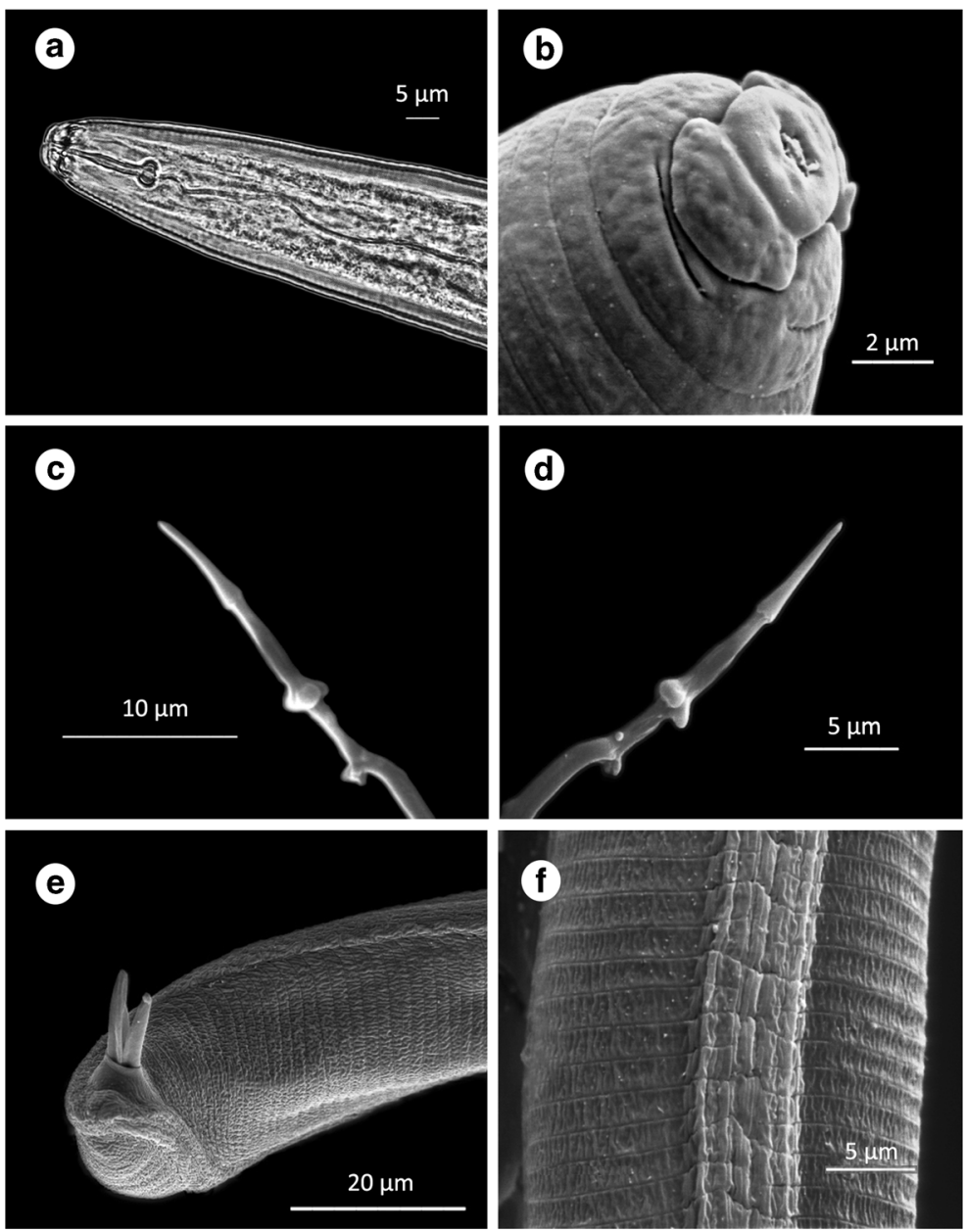

were similar to the original description of $M$. oryzae (Mo) (Maas et al. 1978), with the expected variations that are frequent in the genus Meloidogyne. The populations from Brazil presented a smaller J2 and male length compared to the type population from Suriname, but the other measurements were in the range described for Mo (Table 2).

Meloidogyne oryzae resembles M. graminicola (Mg). The body shape and perineal patterns were similar with some minor variations, but differences are very subjective to differentiate these two species. Mo can be distinguished from $\mathrm{Mg}$ by the stylet and DEGO of females, which is longer $(M o=14-18 \mu \mathrm{m})$ than in $M g(12.6-$ $15.3 \mu \mathrm{m})$. The stylet knobs of $M o$ females are transversely ovoid, backwardly sloping onto shaft; the anterior part of female stylet (conus) is a little shorter than the posterior (shaft) (Fig. 3d-f). Different morphology was observed for $M g$ : the stylet knobs are set off from the shaft and the conus is longer than the shaft (Eisenback and Triantaphyllou 1991). In Mo female lip region is distinctly offset with a very visible and salient annulus; the opposite was observed for $M g$ (Golden and Birchfield 1965). The distance of the DEGO to the base of the stylet is 4-6 $\mu \mathrm{m}$ for M. oryzae and 3-4 $\mu \mathrm{m}$ for M. graminicola (Eisenback and Triantaphyllou 1991). The excretory pore in Mo is located 2-3 stylet lengths behind the anterior apex, and in $M g$ it is situated one and one half stylet lengths (Golden and Birchfield 1965) and, in both cases, anterior to the median bulb. The stylet length $(18-20 \mu \mathrm{m})$ and DEGO $(4-6 \mu \mathrm{m})$ for $M o$ and 16-17 $\mu \mathrm{m}$ and 3-4 $\mu \mathrm{m}$, respectively, for $M g$ (Jepson 1987) can also differentiate these two species. Under SEM, the labial disk and medial lips of males are fused ( $M o$ and $M g$ ), medial lips appear anchor-shaped and separated from labial disk by shallow depression in $\mathrm{Mo}$ and forming a continuous anterior region cap in $\mathrm{Mg}$ 
Fig. 5 Second-stage juvenile of Meloidogyne oryzae from Brazil. a: Light microscopy micrograph of anterior region; $\mathbf{b}$ : Light microscopy micrograph of tail; c, d: Scanning electron microscopy (SEM) micrographs of tail; e: SEM micrograph of anterior region; f: SEM micrograph of lateral field
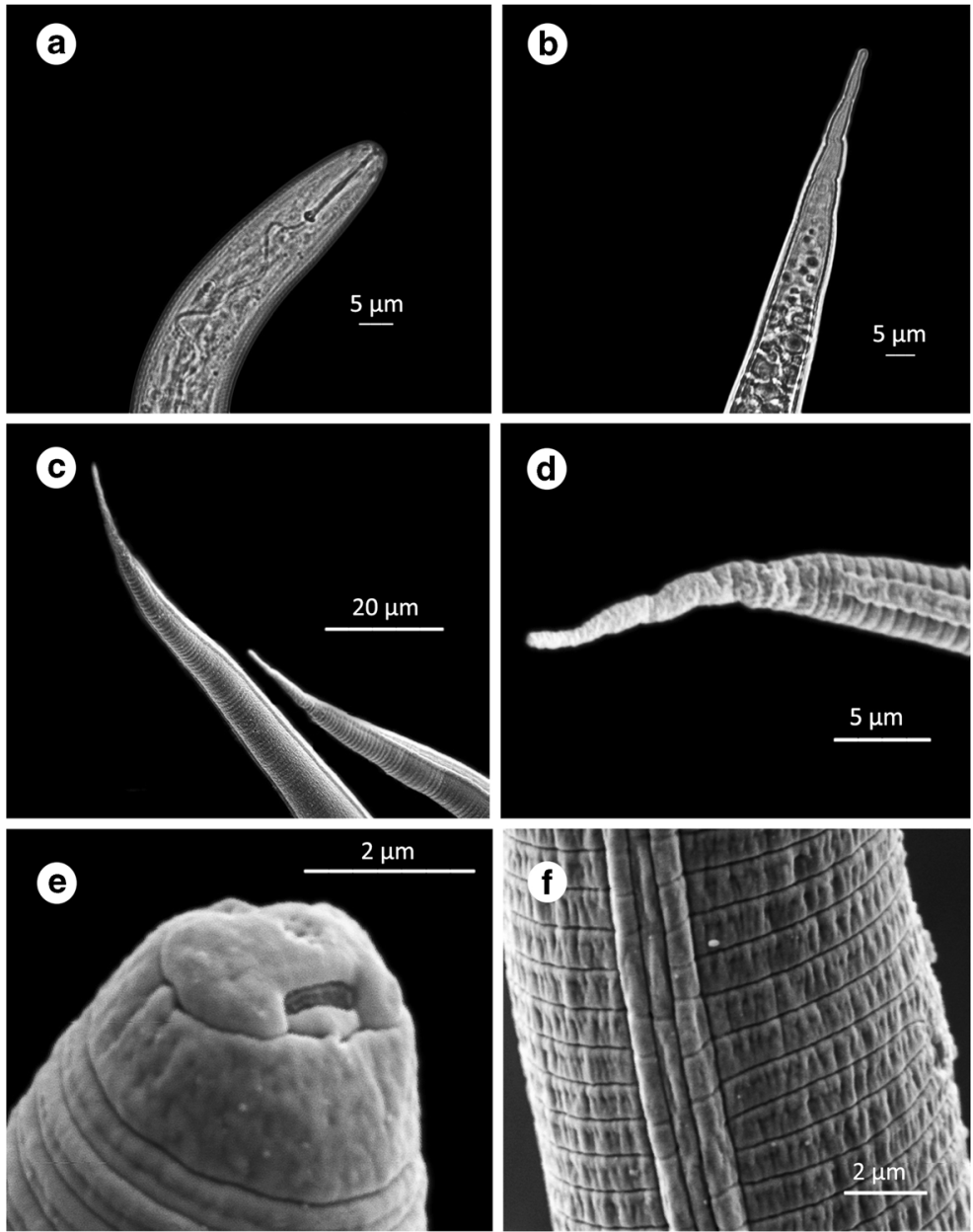

(Jepson 1987). The male anterior region is usually not annulated in $M g$ (Eisenback and Triantaphyllou 1991) and annulated in Mo. In Mo males, the stylet is with knobs offset and slightly irregular, while in $M g$ they are pear shaped, and sloping backwards (Jepson 1987; Eisenback and Triantaphyllou 1991). Second-stage juveniles with average tail length in $M o(75.8 \mu \mathrm{m})$, longer than in $M g(70.9 \mu \mathrm{m})$. A very narrow hyaline tail portion
Fig. 6 Esterase (Est) and malate dehydrogenase (Mdh) phenotypes observed in Meloidogyne spp. populations studied: a: Est M. graminicola (VS1); b: Est of both populations of $M$. oryzae from Brazil (O1);c: Mdh for $M$. graminicola and $M$. oryzae from Brazil (N1a) M. javanica (Est J3 N1) was used as reference

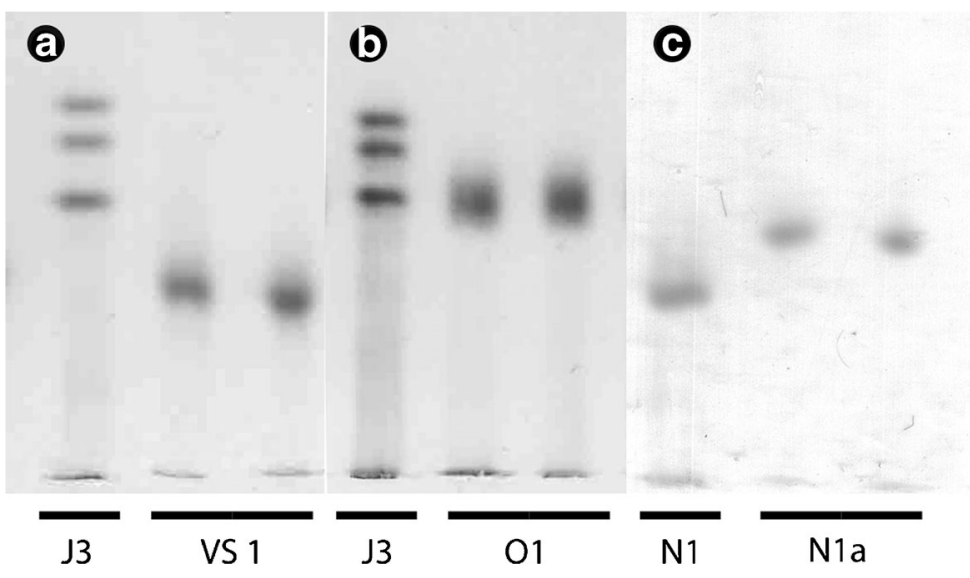




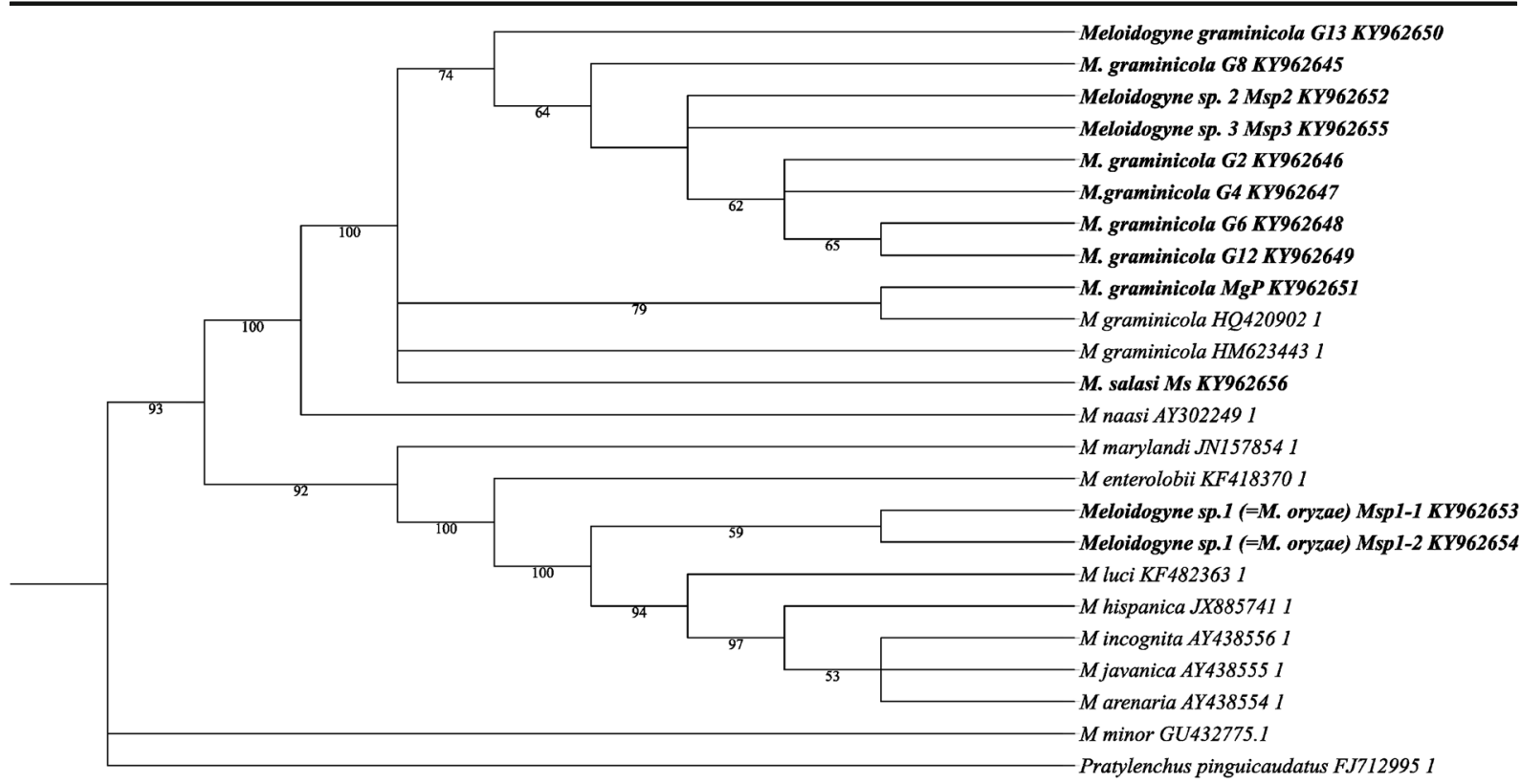

Fig. 7 Neighbour-joining trees showing phylogenetic relationrelated species, based on ITS1-5.8S-ITS2 rRNA sequences ships between Meloidogyne spp. from rice and other closely (Numbers at nodes are bootstrap values (in \%) for 1000 replicates

Fig. 8 Neighbour-joining trees showing phylogenetic relationships between Meloidogyne spp. from rice, based on the combined AFLP and RAPD data set

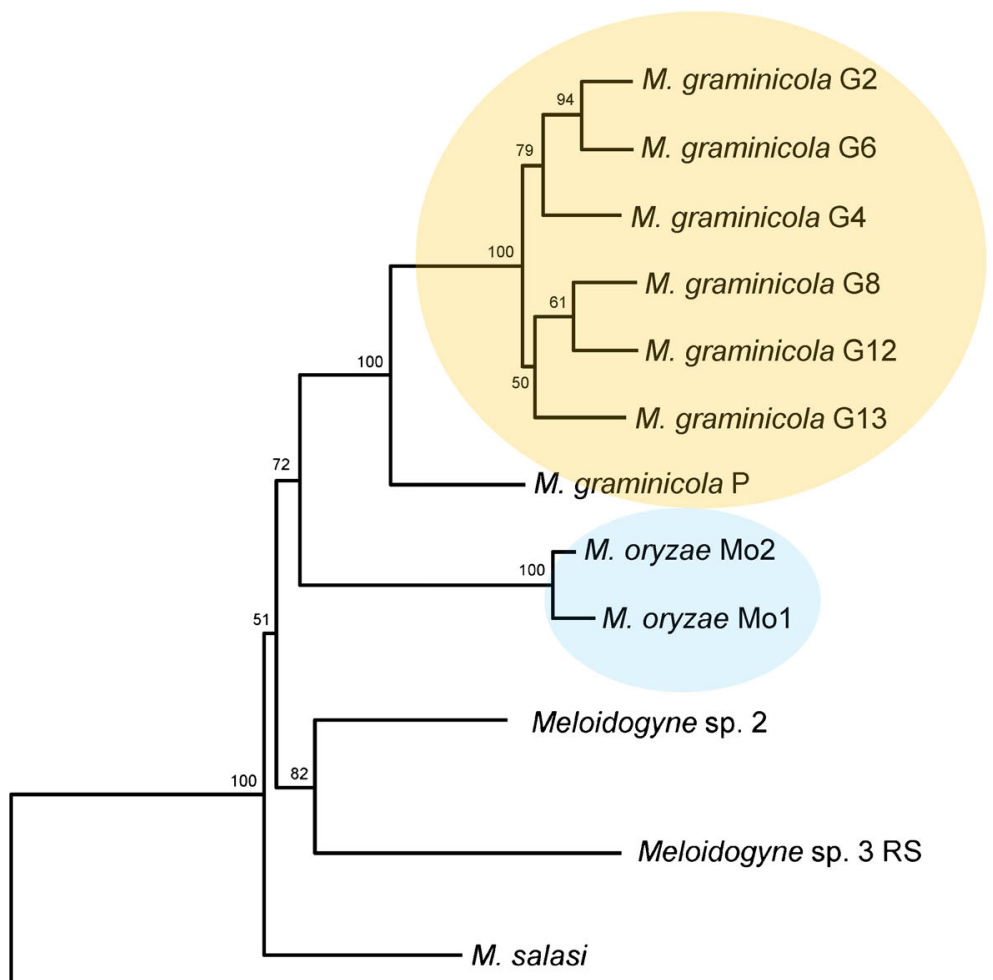

M. incognita

M. javanica 
longer in $M o(22.0 \mu \mathrm{m})$ than in $M g(17.9 \mu \mathrm{m})$ is the most important morphological character to differentiate these two species and Mo from all other Meloidogyne species parasitizing rice (see Discussion). Mo also presents a longer stylet and the rectum dilated, in contrast with $M g$ (Eisenback and Triantaphyllou 1991). Mo presents a specific esterase phenotype profile (Est O1) in contrast with $M g$ (Est VS1) (Fig. 6). In cytogenetic studies, Mo presents $3 \mathrm{n}=50-56$ chromosomes and a mitotic parthenogenesis mode of reproduction, in contrast with $M g$, which reproduces by facultative meiotic parthenogenesis and presents a haploid number of chromosomes $(n=18)$ (Eisenback and Triantaphyllou 1991).

\section{Discussion}

Accurate identification of nematodes is essential for understanding of host-parasite relationships and to implementing appropriate management options. The traditional methods of identification of RKN associated with rice are based on morphology (Jepson 1987; Eisenback and Triantaphyllou 1991), esterase phenotypes (Esbenshade and Triantaphyllou 1985; Carneiro and Almeida 2001) or molecular markers (Bellafiore et al. 2015).

Tail morphology of the second-stage juvenile of M. oryzae places it in Jepson's Group 11 (Jepson 1987) which now includes nine species that parasitize rice and present differential hyaline tail length: $M$. graminicola (17.9 $\mu \mathrm{m})$, M. graminis (Sledge and Golden 1964) Whitehead,1968 (18.5 $\mu \mathrm{m})$, M. hainanensis Liao and

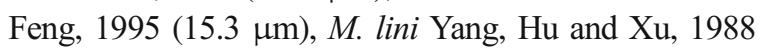
$(\sim 14.0 \mu \mathrm{m})$, M. salasi $(19.7 \mu \mathrm{m})$, M. tritricoryzae Gaur, Saha and Khan, 1993 (17.6 $\mu \mathrm{m})$, M. sasseri Handoo, Huettel and Golden 1995 (19.5 $\mu \mathrm{m})$, M. marylandi Jepson and Golden, $1987(11.8 \mu \mathrm{m})$, and finally the longest in M. oryzae $(22.0 \mu \mathrm{m})$. Most of these species from rice were poorly described and very poorly characterized cytogenetically, enzymatically and molecularly, with the exception of M. graminicola, M. graminis and M. marylandi. Some morphological and biological characters are common in these species: female body elongated, vulva sometimes situated on a posterior protuberance, association with an amphimictic or meiotic parthenogenetic mode of reproduction, semi-endoparasitism, with males abundant; or mitotic parthenogenetic, with males rare and females deeply embedded in the host (Jepson 1987).
In a recent survey in southern Brazil, 56 populations of Meloidogyne spp. were detected in $48 \%$ of rice samples. Meloidogyne sp. 1 (now identified as M. oryzae) occurred in $62.5 \%$ of the samples, frequently in mixture with other species (Negretti et al. 2017), and M. graminicola was the most widespread. In this study, sequencing and phylogenetic analyses of internal transcribed spacer-rRNA (ITS) were performed to infer the phylogenetic relationship of these atypical Meloidogyne spp. populations. Meloidogyne oryzae grouped with the mitotic parthenogenetic species, while $M$. graminicola clustered with other meiotic parthenogenetic species, confirming the results obtained by Negretti et al. (2017).

In general, the morphology and morphometric data of $M$. oryzae populations from Brazil were similar to the original description of $M$. oryzae (Jepson 1987; Maas et al. 1978), with expected variations frequent in the genus Meloidogyne. The populations from Brazil presented a smaller J2 and male compared to the type population from Suriname. This variation in body length can occur in populations of the same species (Handoo et al. 1993). Some authors consider morphological features much more relevant in species characterization than morphometric characters (Jepson 1987; Eisenback and Triantaphyllou 1991). Considering these aspects, $M$. oryzae populations collected in Brazil were very close to the population of M. oryzae detected in Suriname.

Biochemically, M. oryzae and M. graminicola present distinct esterase profiles, with drawn-out bands in different positions. This phenotype was never clearly characterized before and seems to be new and speciesspecific for M. oryzae, (Esbenshade and Triantaphyllou 1985; Carneiro et al. 2000). These authors previously reported a high enzymatic activity in $M$. oryzae and M. graminicola esterase phenotypes, but showing close migration positions.

Meloidogyne oryzae is well adapted to irrigated rice system and also reproduces well on tomato (including the populations from Brazil), differently from M. graminicola (Golden and Birchfield 1965). The populations of $M$. oryzae studied in this work reproduce by mitotic parthenogenesis, present 51-52 chromosomes and clustered in NJ tree/ITS region with mitotic populations, confirming the results obtained by (Esbenshade and Triantaphyllou 1985) and (Negretti et al. 2017) and 
corroborating the contradiction between the generally accepted phylogenic position of $M$. oryzae and its mitotic parthenogenetic mode of reproduction, as highlighted by Castagnone-Sereno et al. 2013.

Neutral molecular markers (AFLP and RAPD) analysis revealed the genetic diversity among the ricerelated Meloidogyne species and sustained the separation between M. graminicola and M. oryzae and the existence of a species complex in rice as already detected in Negretti et al. 2017.

All the mitotic parthenogenetic forms have probably evolved from meiotic parthenogenetic ancestors or, less likely, from amphimitic ones, following suppression of the meiotic process during maturation of the oocytes. The variation in chromosome numbers observed among the mitotic parthenogenetic forms suggests several pathways of derivation. Species with about 51-56 chromosomes like M. oryzae could be considered as triploids, and they were most likely derived following hybridization of meiotic parthenogenetic forms like M. graminicola, involving, for example, the fertilization of an unreduced egg with $36(18+18)$ chromosomes, with a normal sperm having 18 chromosomes (Triantaphyllou 1985a). This evolutionary phenomenon could explain the simultaneous occurrence of $M$. oryzae and M. graminicola in the same areas in the state of Santa Catarina (Negretti et al. 2017) and there is probably a speciation process occurring in these Brazilian rice fields.

Finally, our results clarified the taxonomic position of $M$. oryzae, and illustrated the interest of using integrative taxonomy for accurate species description (Padial et al. 2010; Pante et al. 2015). Indeed, detailed morphological, morphometric, cytological and molecular studies were performed to correctly characterize this nematode from rice fields. Precise identification of nematode species is important to elucidate future biological or agronomic studies in order to clarify the distribution and importance of this species in the field, and thus to plan efficient control measures for the management of this disease in the southern region of Brazil.

Acknowledgements This work was supported by Conselho Nacional de Desenvolvimento Científico e Tecnológico - CNPq (PROTAX/CNPq Grant \# 562346/2010-4), EMBRAPA — Recursos Genéticos e Biotecnologia and Fundação de Apoio à Pesquisa do Distrito Federal (FAP-DF). V.S. Mattos, G.M. Gomez and R.M.D.G. Carneiro thank CNPq for their scholarships.

\section{References}

Araki, M. (1992). Description of Meloidogyne ichinohei n. sp. (Nematoda:Meloidogynidae) from Iris laevigata in Japan. Japanese Journal of Nematology, 22, 11-20.

Bellafiore, S., Jougla, C., Chapuis, E., Besnard, G., Suong, M., Vu, P. N., De Whale, D., Gantet, P., \& Thi, X. N. (2015). Intraspecific variability of the facultative meiotic parthenogenetic root-knot nematode (Meloidogyne graminicola) from rice fields in Vietnam. Comptes Rendus Biologies, 338, 471-483.

Carneiro, R. M. D. G., \& Almeida, M. R. A. (2001). Técnica de eletroforese usada no estudo de enzimas dos nematoides de galhas para identificação de espécies. Nematologia Brasileira, 25(1), 35-44.

Carneiro, R. M. D. G., Castagnone-Sereno, P., \& Dickson, D. W. (1998). Variability among four populations of Meloidogyne javanica from Brazil. Fundamental and Applied Nematology, 21, 319-326.

Carneiro, R. M. D. G., Almeida, M. R. A., \& Quénéhervé, P. (2000). Enzyme phenotypes of Meloidogyne spp. populations. Nematology, 2, 645-654.

Castagnone-Sereno, P., Danchin, E. G., Perfus-Barbeoch, L., \& Abad, P. (2013). Diversity and evolution of root-knot nematodes, genus Meloidogyne: new insights from the genomic era. Annual Review of Phytopathology, 51, 203-220.

Coetzee, V. (1956). Meloidogyne acronea, a new species of rootknot nematode. Nature, 4515, 899-900.

De Ley, P., Felix, M. A., Frisse, L. M., Nadler, S. A., Stember, P. W., \& Thomas, W. K. (1999). Molecular and morphological characterisation of two reproductive species with mirrorimage anatomy (Nematoda: Cephalobidae). Nematology, 1, 591-612.

De Waele, D., \& Elsen, A. (2007). Challenges in tropical plant nematology. Annual Review of Phytopathology, 45, 457-485.

Eisenback, J. D., \& Hirschmann, H. (1979). Morphological comparison of second-stage juveniles of six populations of Meloidogyne hapla by SEM. Journal of Nematology, 11, 5-16.

Eisenback, J. D., \& Hirschmann, H. (1980). Morphological comparison of Meloidogyne males by scanning electron microscope. Journal of Nematology, 12, 23-32.

Eisenback, J. D., \& Triantaphyllou, H. H. (1991). Root-knot nematode: Meloidogyne spp. and races. In W. R. Nickle (Ed.), Manual of agricultural nematology (pp. 191-274). New York: Marcel Dekker.

Eisenback, J. D., Hirschmann, H., \& Triantaphyllou, A. C. (1980). Morphological comparison of Meloidogyne female lip region structures, perineal patterns, and stylets. Journal of Nematology, 12, 300-313.

Esbenshade, P. R., \& Triantaphyllou, A. C. (1985). Use of enzyme phenotypes for identification of Meloidogyne species. Journal of Nematology, 17, 6-20.

Golden, A. M., \& Birchfield, W. (1965). Meloidogyne graminicola (Heteroderidae), a new species of root-knot nematode from grass. Proceedings of the Helminthological Society of Washington, 32, 228-231.

Handoo, Z. A., Huettel, R. N., \& Golden, A. M. (1993). Description and SEM observations of Meloidogyne sasseri n. sp. (Nematoda: Meloidogynidae), parasitizing beachgrasses. Journal of Nematology, 25(4), 628. 
Huelsenbeck, J. P., Bull, J. J., \& Cunningham, C. W. (1996). Combining data in phylogenetic analysis. Trends in Ecology \& Evolution, 11(4), 152-158.

Hunt, D. J., \& Handoo, Z. A. (2009). Taxonomy, identification and principal species. In R. N. Perry, M. Moens, \& J. L. Starr (Eds.), Root-Knot Nematodes (pp. 55-97). Wallingford: CABI.

Jepson, S. B. (1987). Identification of root-knot nematodes (Meloidogyne species). Wallingford: CAB International.

Maas, P. W. T., Sanders, H., \& Dede, J. (1978). Meloidogyne oryzae n. sp. (Nematoda, Meloidogynidae) infesting irrigated rice in Surinam (South America). Nematologica, $24,305-311$.

Negretti, R. R., Gomes, C. B., Mattos, V. S., Somavilla, L., Manica-Berto, R., Agostinetto, D., Castagnone-Sereno, P., \& Carneiro, R. M. D. G. (2017). Characterisation of a Meloidogyne species complex parasitising rice in southern Brazil. Nematology, 19, 403-412.

Padial, J. M., Miralles, A., De la Riva, I., \& Vences, M. (2010). The integrative future of taxonomy. Frontiers in Zoology, 7(1), 16.

Page, S. L. J. (1985). Meloidogyne acronea. In: CIH Descriptions of Plant-parasitic Nematodes, Set 8, No.114. Commonwealth Agricultural Bureaux, Farnham Royal.

Pante, E., Schoelinck, C., \& Puillandre, N. (2015). From integrative taxonomy to species description: one step beyond. Systematic Biology, 64, 152-160.

Plantard, O., Valette, S., \& Gross, M. F. (2007). The root-knot nematode producing galls on Spartina alterniflora belongs to the genus Meloidogyne: Rejection of Hypsoperine and Spartonema spp. Journal of Nematology, 39, 127-132.

Randig, O., Bongiovanni, M., Carneiro, R. M. D. G. \& Castagnone-Sereno, P. (2002). Genetic diversity of rootknot nematodes from Brazil and development of SCAR markers specific for the coffee-damaging species. Genome, $45,862-870$.

Saitou, N., \& Nei, M. (1987). The Neighbor-Joining method, a new method for reconstructing phylogenetic trees. Molecular Biology and Evolution, 4, 406-425.
Schmitz, B., Burgermeister, W., \& Braasch, H. (1998). Molecular genetic classification of Central European Meloidogyne chitwoodi and M. fallax populations. Nachrichtenblatt des Deutschen Pflanzenschutzdienstes, 50, 310-317.

Siddiqi, M. R. (2000). Tylenchida: parasites of plants and insects (2nd ed.). Wallingford: CABI.

Suazo, A. \& Hall, H. G. (1999). Modification of the AFLP protocol applied to honey bee (Apis mellifera L.) DNA. Biotechniques, 26(4), 704-705.

Subbotin, S., Waeyenberge, A.L. \& Moens, M. (2000). Identification of cyst forming nematodes of the genus Heterodera (Nematoda: Heteroderidae) based on the ribosomal DNA RFLPs. Nematology, 2, 153-164.

Swofford, D. L. (2002). PAUP*: phylogenetic analysis using parsimony (*and other methods). Version $4 b 10$. Massachusetts: Sinauer Associates.

Tamura, K., Peterson, D., Peterson, N., Stecher, G., Nei, M., \& Kumar, S. (2011). MEGA5: molecular evolutionary genetics analysis using maximum likelihood, evolutionary distance, and maximum parsimony methods. Molecular Biology and Evolution, 28, 2731-2739.

Taylor, D. P., \& Netscher, C. (1974). An improved technique for preparing perineal patterns of Meloidogyne spp. Nematologica, 20, 268-269.

Tigano, M. S., Carneiro, R. M. D. G., Jeyaprakash, A., Dickson, D. W., \& Adams, B. J. (2005). Phylogeny of Meloidogyne spp. based on $18 \mathrm{~S}$ rDNA and the intergenic region of mitochondrial DNA sequences. Nematology, 7(6), 851-862.

Triantaphyllou, A. C. (1985a). Cytogenetics, cytotaxonomy and phylogeny of root-knot nematodes. In J. N. Sasser \& C. C. Carter (Eds.), An Advanced Treatise on Meloidogyne. Vol. I. Biology and Control (pp. 113-126). Raleigh: North Carolina State University Graphics.

Triantaphyllou, A. C. (1985b). Cytological methods for the study of oogenesis and reproduction of root-knot nematodes. In K. R. Barker, C. C. Carter, \& J. N. Sasser (Eds.), An advanced treatise on Meloidogyne: Methodology (Vol. 2, pp. 107-114). Raleigh: North Carolina State University Graphics. 